\title{
FATORES DE RISCO PARA O TRANSTORNO MENTAL RELACIONADO AO TRABALHO EM PROFISSIONAIS DE ENFERMAGEM
}

\author{
RISK FACTORS FOR MENTAL DISORDERS RELATED TO WORK IN NURSING PROFESSIONALS
}

\section{Carolina Silva Munhoza , Talita Golçalves Moreira Dantas, Luz Alcira Ávila Rínconc, Silvana Togninid}

amunhoz.carolina@hotmail.com, btalitadantas74@gmail.com, cluzalcira@uscs.edu.br, dsilvana.tognini@uscs.edu.br Universidade Municipal de São Caetano do Sul, São Caetano do Sul (SP), Brasi

Data de recebimento do artigo: 21/02/2018 Data de aceite do artigo: 02/04/201

\section{RESUMO}

Introdução: $\mathrm{O}$ trabalho satisfaz as mais diversas necessidades humanas; por outro lado pode ser fonte de adoecimento quando o trabalhador fica exposto aos riscos inerentes às suas atividades. $\mathrm{O}$ estresse no ambiente laboral pode desencadear transtornos mentais relacionados ao tempo de permanência e a intensidade do serviço. A síndrome de Burnout é o distúrbio mais referido entre profissionais de enfermagem. Objetivo: Realizar revisão sistemática da literatura sobre os fatores de risco do transtorno mental relacionado ao trabalho em profissionais da enfermagem. Materiais e métodos: Revisão da literatura publicada no período de 2009 a 2017. Utilizaram-se as bases de dados LILACS, BDENF e SciELO, e o cruzamento dos descritores "enfermagem" e "esgotamento profissional". Resultados: Foram evidenciados diversos fatores que alteram o nível de estresse do enfermeiro e da sua equipe relacionados a pressão da carga de trabalho, esforço físico, acúmulo de funções, sobrecarga emocional, conflitos nas relaçôes interpessoais, entre outros agravantes que interferem negativamente na qualidade de vida dos trabalhadores, assim como foi citada na maior parte dos artigos de revisão a ocorrência da síndrome de Burnout entre as consequências impostas no trabalho da classe trabalhadora estudada. Conclusáo: Ressalta-se a importância de pesquisas sobre o tema a fim de contribuir para a construçáo de políticas públicas de saúde e o fortalecimento das açóes em segurança e saúde do trabalhador da enfermagem.

Palavras-chave: Transtorno mental; enfermagem; estresse; riscos ocupacionais, saúde do trabalhador.

\begin{abstract}
Introduction: Working satisfies the most diverse human needs; on the other hand, it can be a source of illness when the worker is exposed to the risks inherent to their activities. Stress in the work environment can trigger mental disorders related to length of stay and intensity of work. Burnout Syndrome is the most commonly reported disorder among nursing professionals. Objective: To carry out a systematic review of the literature on the risk factors of work-related mental disorders in nursing professionals. Materials and methods: Review of the literature published in the period from 2009 to 2017 . The databases LILACS, BDENF and SciELO were used and the descriptors "nursing" and "professional exhaustion" were cross-referenced. Results: There were several factors that alter the level of stress of the nurse and his/her team, related to workload pressure, physical effort, accumulation of functions, emotional overload, conflicts in interpersonal relations, among other aggravating factors that interfere negatively in the workers quality of life, as mentioned in most of the reviewed articles, the occurrence of Burnout Syndrome among the consequences imposed on the work of the working class studied. Conclusion: The importance of research on the study should be emphasized, in order to contribute to the construction of public health policies and to the strengthening of actions in the health and safety of nursing workers.
\end{abstract}

Keywords: Mental disorder; nursing; stress; occupational risks; occupational health. 


\section{Introdução}

O trabalho apresenta-se como elemento central da vida do homem moderno, ocupando grande parte de sua existência ${ }^{1,2}$. Porém, o homem (pós)moderno é vítima das doenças profissionais náo por consequência de uma ocupação, mas por não aprender a (con)viver com os seus efeitos ${ }^{3}$.

No ano de 2010, mais de 2,2 milhóes de novos benefícios auxílios-doença foram concedidos para uma população de aproximadamente 60 milhóes de contribuintes ${ }^{4}$. Segundo o Anuário Estatístico da Previdência Social de 2011, mais de 211 mil pessoas foram afastadas em razão de transtornos mentais e comportamentais (CID 10/F00-F99), gerando um gasto de R \$ 213 milhōes em pagamentos de benefícios ${ }^{5}$. Esse crescente ônus representa um custo enorme em termos de sofrimento humano, incapacidade e prejuízos econômicos, pois, além de comprometer a saúde das populaçóes, representa uma elevada despesa para a saúde pública ${ }^{6}$.

De acordo com os dados da Empresa de Processamento de Dados da Previdência Social (Dataprev), entre os meses de janeiro e abril de 2014, acerca dos acompanhamentos mensais dos benefícios auxílios-doença previdenciários concedidos, os transtornos mentais e comportamentais ocuparam o terceiro lugar em número de auxílios-doença concedidos pela Previdência Social no Brasil ${ }^{7}$.

A exposição contínua e prolongada a fatores de risco presentes no ambiente laboral favorece o surgimento de doenças relacionadas ao trabalho, que são frequentemente responsáveis por afastamentos, licenças médicas ou até mesmo aposentadorias por invalidez ${ }^{8}$.

Os primeiros relatos que abordam a questão das doenças relacionadas ao trabalho datam do século XVII. No fim desse século (1700), Bernardino Ramazzini, famoso médico italiano, publicou a obra As doenças dos trabalhadores, na qual relatou mais de cinquenta doenças relacionadas ao trabalho, ${ }^{9,10}$. Foi por meio dessa publicação que ficou conhecida a famosa frase: "Digas qual o seu trabalho, que direis os riscos que estais sujeitos" ${ }^{11}$. Ramazzini possuía um método de observação empírica cuja base de sua pesquisa pautava na observaçáo minuciosa do doente e no ofício causador da doença, seguindo assim uma descrição ordenada, coerente e abrangen$t^{12}$. Devido à importância da obra, Ramazzini ficou conhecido como o "Pai da Medicina do Trabalho"13.

$\mathrm{Na}$ atualidade, o professor René Mendes, com base na linha de raciocínio de Bernardino Ramazzini, afirma que as inter-relaçóes entre ambiente de trabalho e fatores de riscos ocupacionais nele presente podem representar perigo náo apenas para o empreendimento da empresa, como para as comunidades vizinhas afetadas indiretamente ${ }^{14}$.
$\mathrm{Na}$ enfermagem, a exemplo de outras áreas de atuação profissional, o estresse ocupacional se faz presente, sendo um dos maiores e recorrentes causas de adoecimento mental ${ }^{15}$. Existem diferentes motivos que podem comprometer a saúde do trabalhador da enfermagem em seu ambiente laboral, provenientes dos conflitos entre a profissáo e o sistema em que ela está inserida ${ }^{16}$.

Devido à responsabilidade pela vida das pessoas e à proximidade com a dor e o sofrimento alheio, os profissionais de enfermagem lidam, frequentemente, com situações diversificadas no exercício de suas atividades, o que pode ocasionar esgotamento físico e mental, sendo expostos a outros fatores estressores, como situação de riscos químicos e físicos, além de contato com equipamentos inadequados ${ }^{17}$.

Algumas das condições laborais fortemente relacionadas ao adoecimento mental do enfermeiro são: deficiências de recursos humanos, problemas de relacionamento, ambiguidade de papéis, ritmo excessivo de trabalho, jornadas longas, duplas ou triplas, pouco tempo para o descanso diário necessário para a recuperação etc ${ }^{18}$.

O estudo da manifestaçáo do estresse ocupacional entre enfermeiros pode ajudar a compreender melhor e a elucidar alguns dos problemas enfrentados pela profissão, tais como insatisfação profissional, produção no trabalho, absenteísmo, acidentes de trabalho e algumas doenças laborais ${ }^{19}$.

O estresse em alto grau pode evoluir para a síndrome de Burnout $(\mathrm{SB})^{20}$. A SB ou síndrome do cansaço exaustivo é uma doença característica de profissionais que trabalham com o público, pois, apesar de todo o esforço para alcançar as metas, o trabalhador não se sente recompensado e reconhecido, resultando em falta de interesse pela função, manifestação de transtornos mentais e físicos, entre outros sintomas ${ }^{21}$. Em trabalhadores da enfermagem, além de ser nocivo nos planos individual e de categoria profissional, esse problema pode refletir negativamente na qualidade da assistência de enfermagem prestada aos pacientes e familiares nos serviços de saúde, numa época em que tanto se privilegia a humanização da assistência à saúde ${ }^{22}$.

\section{Objetivos}

O estudo teve como objetivo realizar revisão da literatura, em especial brasileira, para conhecer os fatores de risco de adoecimento mental dos profissionais de enfermagem, especificamente no que diz respeito à $S B$, suas implicações no ambiente laboral e as estratégias de intervenção utilizadas para amenizar os riscos no ambiente de trabalho. 


\section{Métodos}

Trata-se de pesquisa de revisão bibliográfica. Para desenvolver a revisão da literatura foi utilizado o Portal da Biblioteca Virtual de Saúde (BVS) como base estratégica, no qual três bases de dados escolhidas foram consultadas: Literatura Latino Americana e do Caribe em Ciências da Saúde (LILACS), Base de Dados de Enfermagem (BDENF) e Scientific Electronic Library Online (SciELO).

Para completar a fundamentação teórica deste estudo, foram feitas, além da busca nas bases de dados, consultas de obras em livros e publicaçóes de artigos científicos, assim como informativos do Conselho Regional de Enfermagem (Coren), Ministério da Previdência Social (MPS), teses e dissertações, entre outros com confiabilidade segura e evidência científica aprovada.

A pesquisa foi realizada considerando o ano de 2017, abrangendo os artigos nacionais publicados entre o período de 2009 a 2017, restringindo-se às publicaçôes de enfermagem. Utilizou-se o banco de dados dos Descritores em Ciências da Saúde (DeCS): "transtorno mental", "enfermagem", "estresse", "riscos ocupacionais" e "saúde do trabalhador".

Foram localizados 1.062 artigos relacionados ao descritor "esgotamento profissional". Quando associado ao descritor "enfermagem", filtrou-se 93 produções. Foram encontrados 19 textos na base de dados LILACS, 57 no SciELO e 17 na BDENF. Dos 93 artigos encontrados, somente 21 foram selecionados e utilizados por serem pertinentes ao objetivo proposto pelo estudo, seguido do período de publicaçáo com datas mais recentes e por apresentarem conteúdos na íntegra.

Os critérios de exclusão dos artigos foram: estudos que consideravam outras categorias profissionais, publicados fora do tempo determinado para busca, que náo apresentavam conteúdo na íntegra, inclusive aqueles que estavam repetidos em mais de um banco de dados (sendo contabilizados apenas uma vez).

Após seleção e leitura dos 21 artigos na íntegra, foram formuladas as discussóes sobre as principais características e conclusóes do estudo apontadas no Quadro 1. Foi observada, durante a construçáo da pesquisa científica, a escassez sobre o tema no Brasil. O estudo privilegiou o país, tendo em vista que o interesse nesta pesquisa foi compreender o tema sob a ótica dos autores nacionais.

Os dados coletados foram analisados por meio de quadro estruturado de acordo com a proposta da pesquisa, sendo apresentado conforme categoria dos dados das publicaçôes: título; autores; periódico e síntese das conclusóes.

\section{Discussão}

Entre os trabalhadores envolvidos diretamente com a assistência ao paciente, o enfermeiro e a equipe de enfermagem demonstraram os maiores índices de exaustáo emocional, despersonalização e baixo nível de realização profissional $^{30}$.

Estudos reafirmam a importância de analisar a natureza psicossocial do trabalho, pois essa investigaçáo poderá contribuir de forma significativa para a melhor qualidade de vida dos trabalhadores de enfermagem, assim como para o fortalecimento das açóes em saúde do trabalhador ${ }^{33,36}$.

Entre os estudos analisados no Quadro 1, evidenciou-se a presença de fatores que alteram o nível de estresse do enfermeiro dados os aspectos inerentes a profissão ${ }^{24}$, caracterizados por acúmulo de funções e intensa sobrecarga emocional, predominante em setores de vulnerabilidade dos pacientes, inclusive por cobranças administrativas e exigência técnica-científica profissional ${ }^{27,29,31}$.

Em geral o nível de estresse do enfermeiro apresenta nível moderado a elevado ${ }^{23}$. Os fatores de risco para seu adoecimento mental se referem a pressáo da carga de trabalho, deslocamento, esforço físico, trabalho repetitivo e supervisão da equipe ${ }^{26}$.

Situaçóes geradoras de conflitos nas relaçóes interpessoais, caracterizadas por conflitos com chefia, administração e representação do poder de maneira abusiva, ofensiva e humilhante, corroboram para a alteração do nível de estresse, favorecendo o desgaste físico, emocional, mental e, consequentemente, o surgimento de doenças ocupacionais ${ }^{32,37,39}$. Indivíduos jovens, do gênero feminino, solteiros, sem filhos, recém-formados e inseridos em setores de alta complexidade estão mais propensos a desenvolver a $\mathrm{SB}^{38}$. Essa síndrome é citada na maior parte dos artigos em revisão como a doença ocupacional de maior ocorrência, visto que o estresse em excesso ou os seus fatores expostos sobre o trabalhador com frequência podem vir a desencadeá-la.

Esses fatores interferem de maneira negativa na qualidade de vida e saúde do trabalhador, contribuindo para falta de motivação, irritaçóes frequentes, frustraçáo, dores musculares, assim como sinais e sintomas característicos do estresse ${ }^{41}$. Enfermeiros que trabalham em plantão noturno sofrem com alteração do padrão do sono, mudanças nos hábitos de alimentação, mudanças de humor, irritabilidade, cansaço e diminuição da capacidade de concentração ${ }^{34}$. Com isso os resultados negativos envolvem não só o profissional em questão, mas também os pacientes e a instituição na medida em que são afetados e prejudicados ${ }^{40}$. 


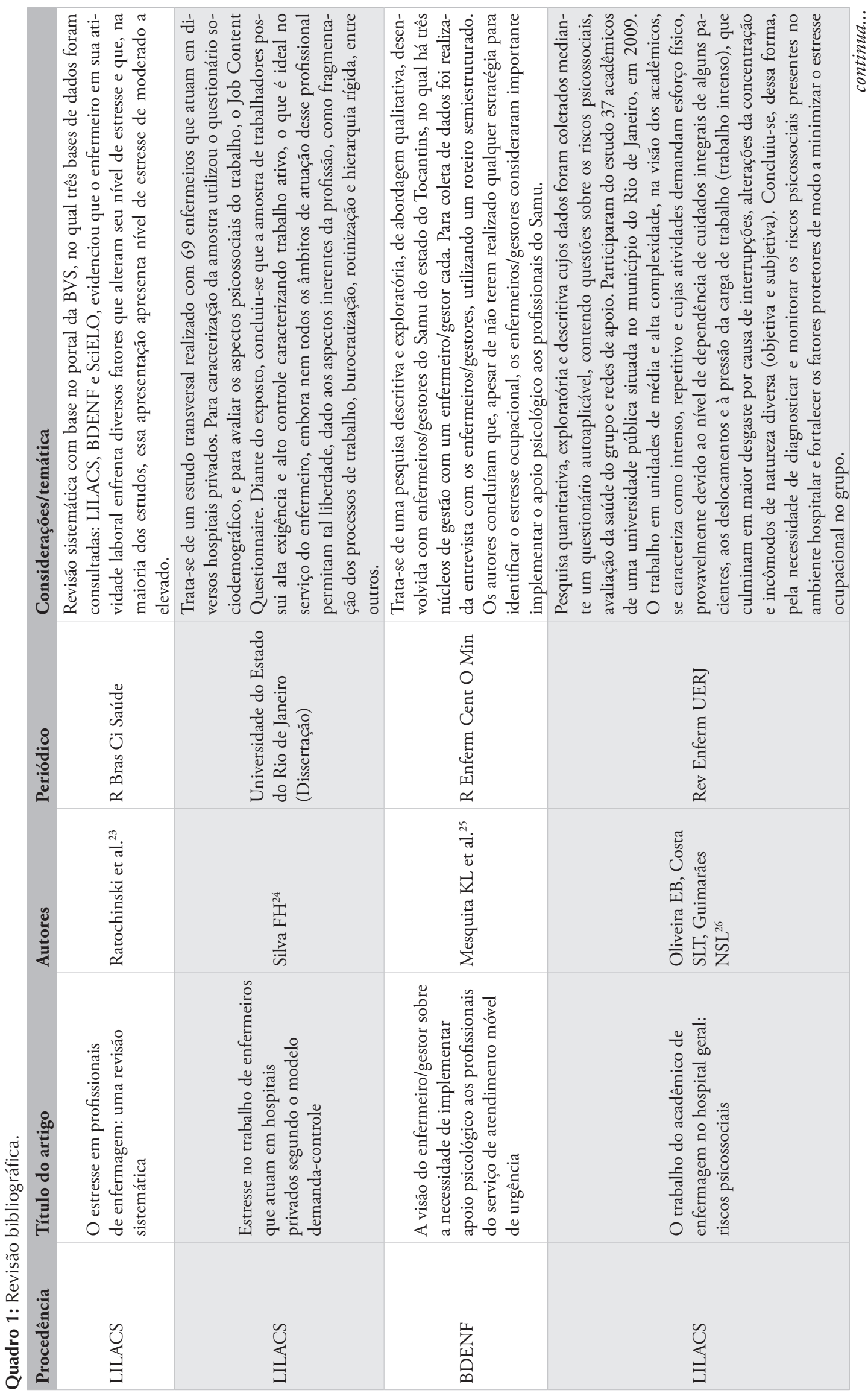




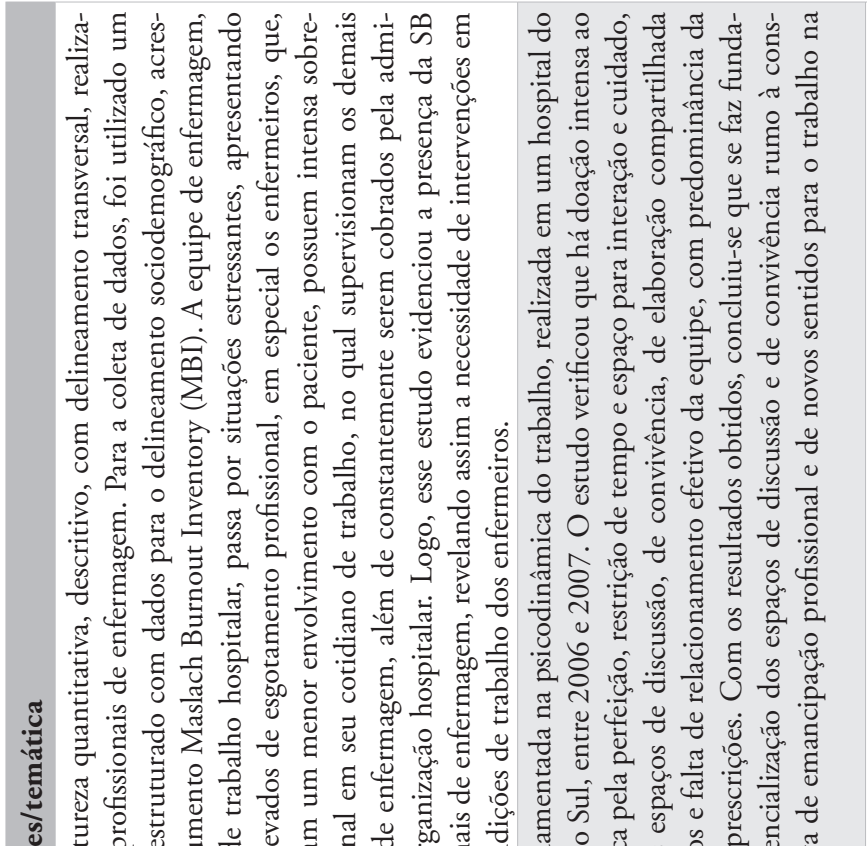

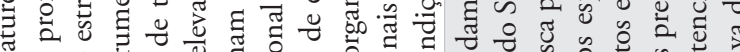

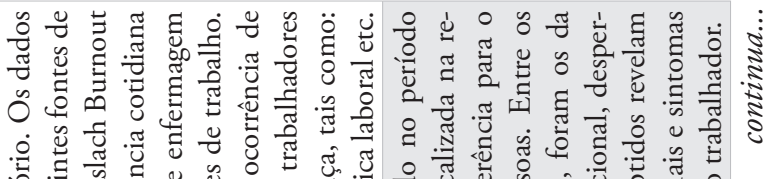

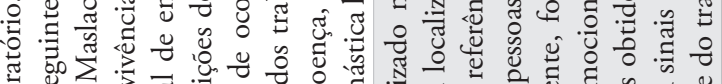

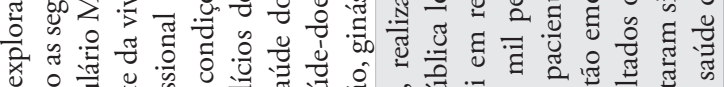

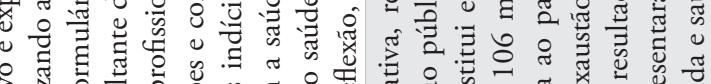

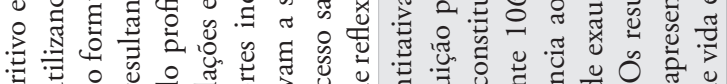

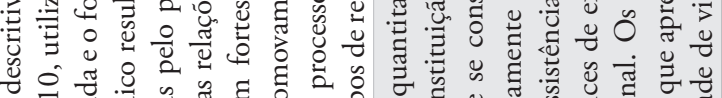

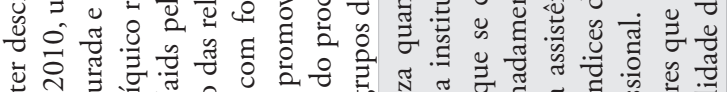

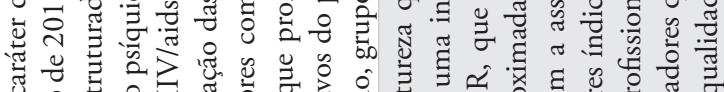

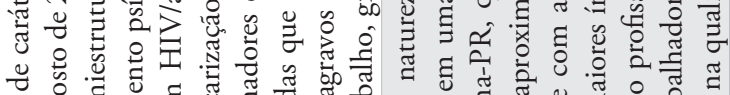

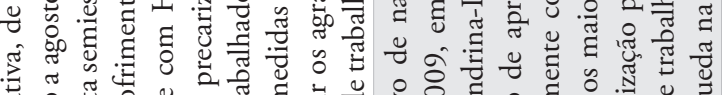

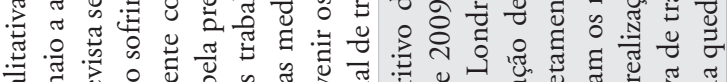

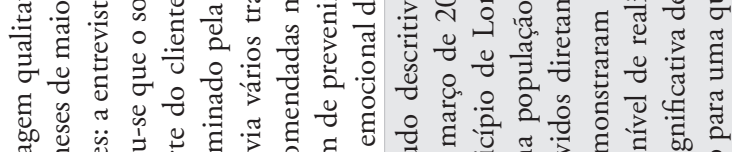

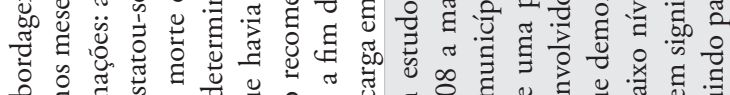

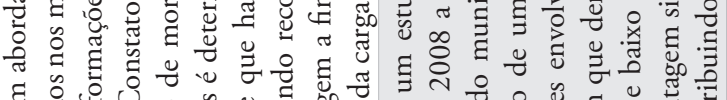

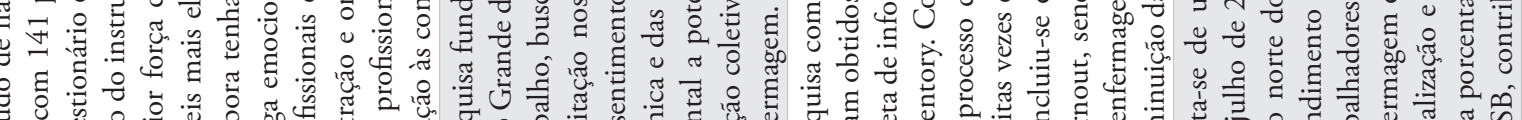

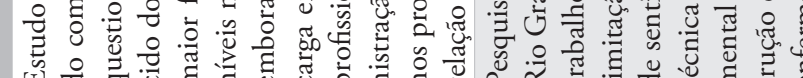

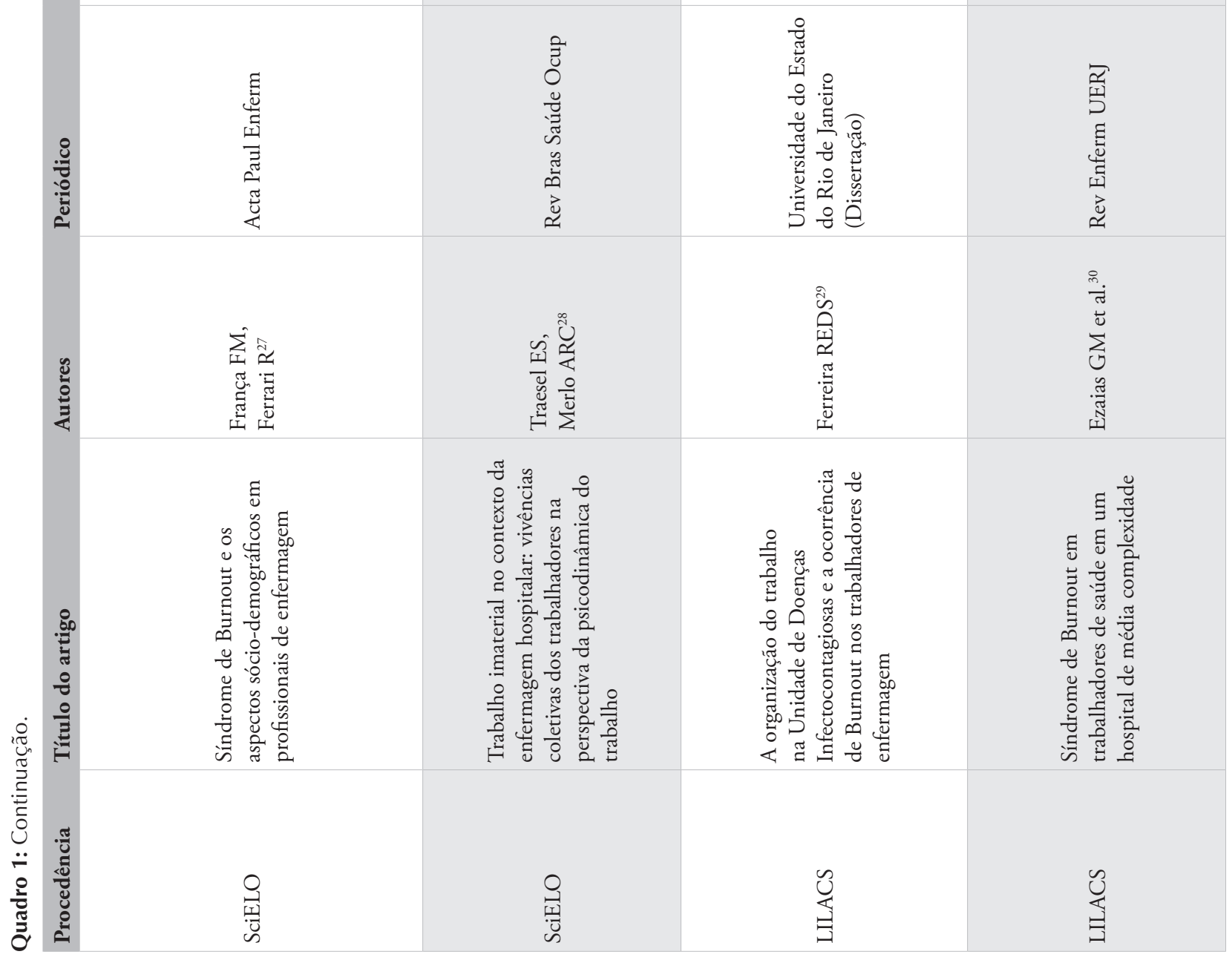



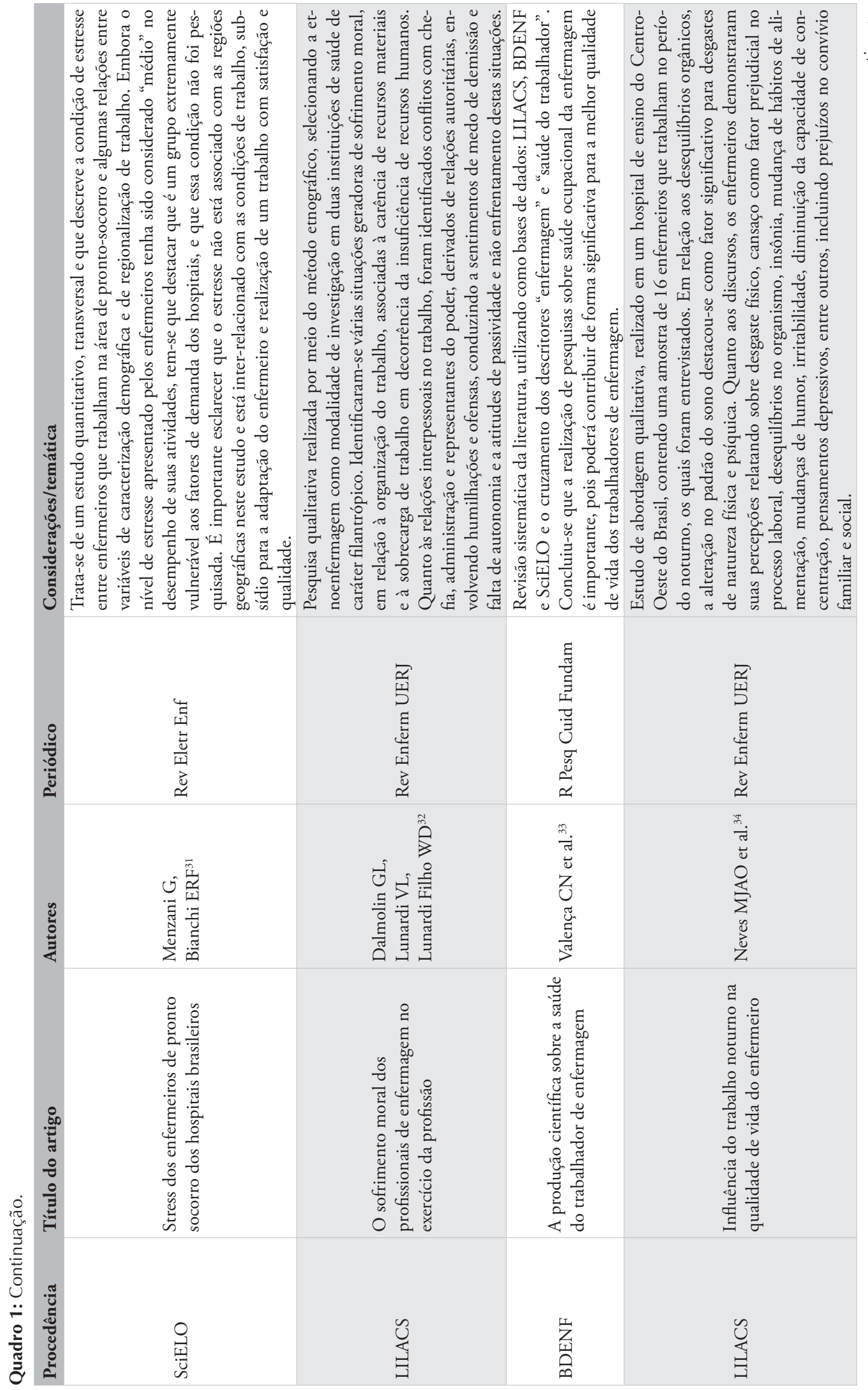


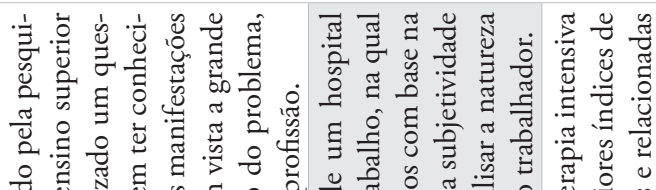

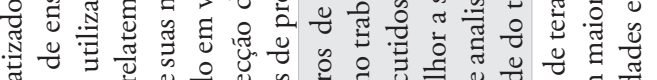

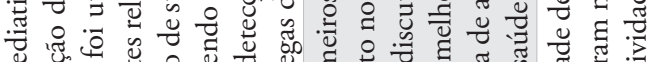

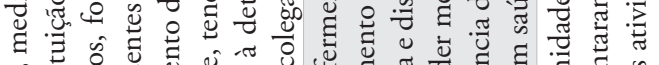

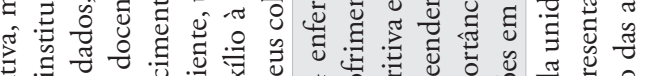

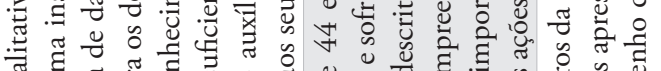

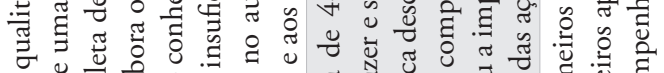

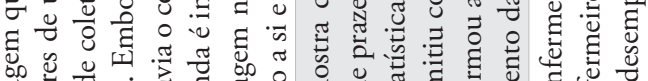

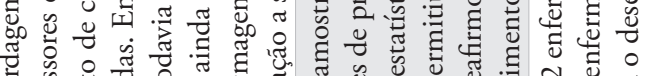

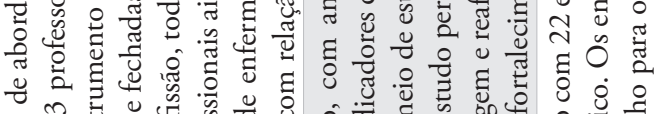

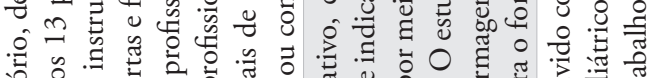

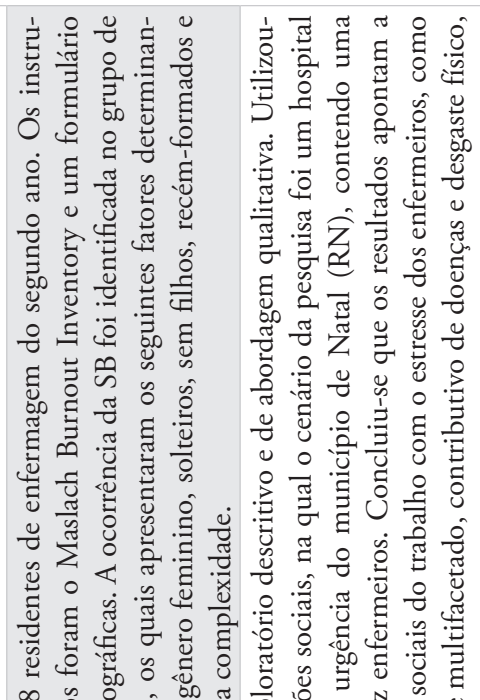

๘

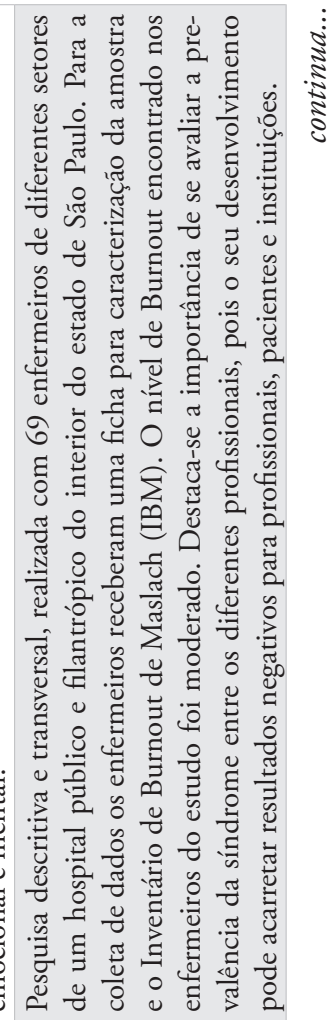

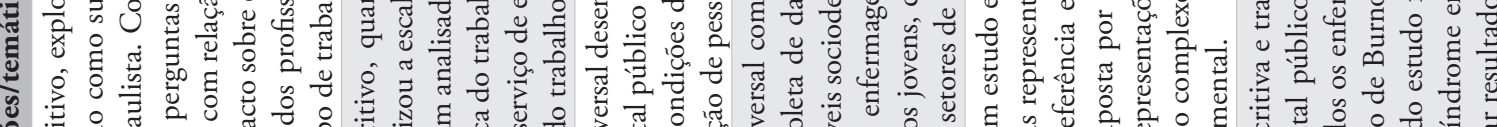

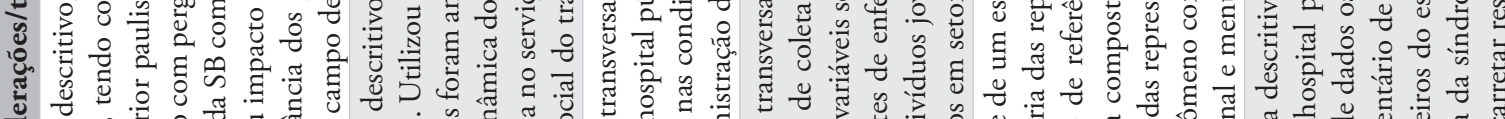

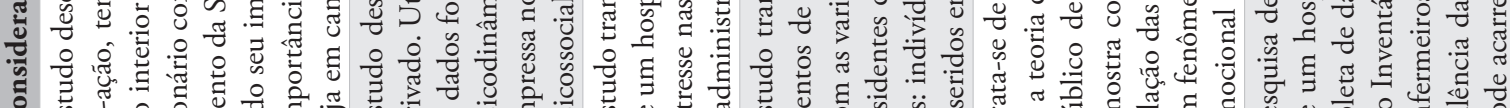
ن

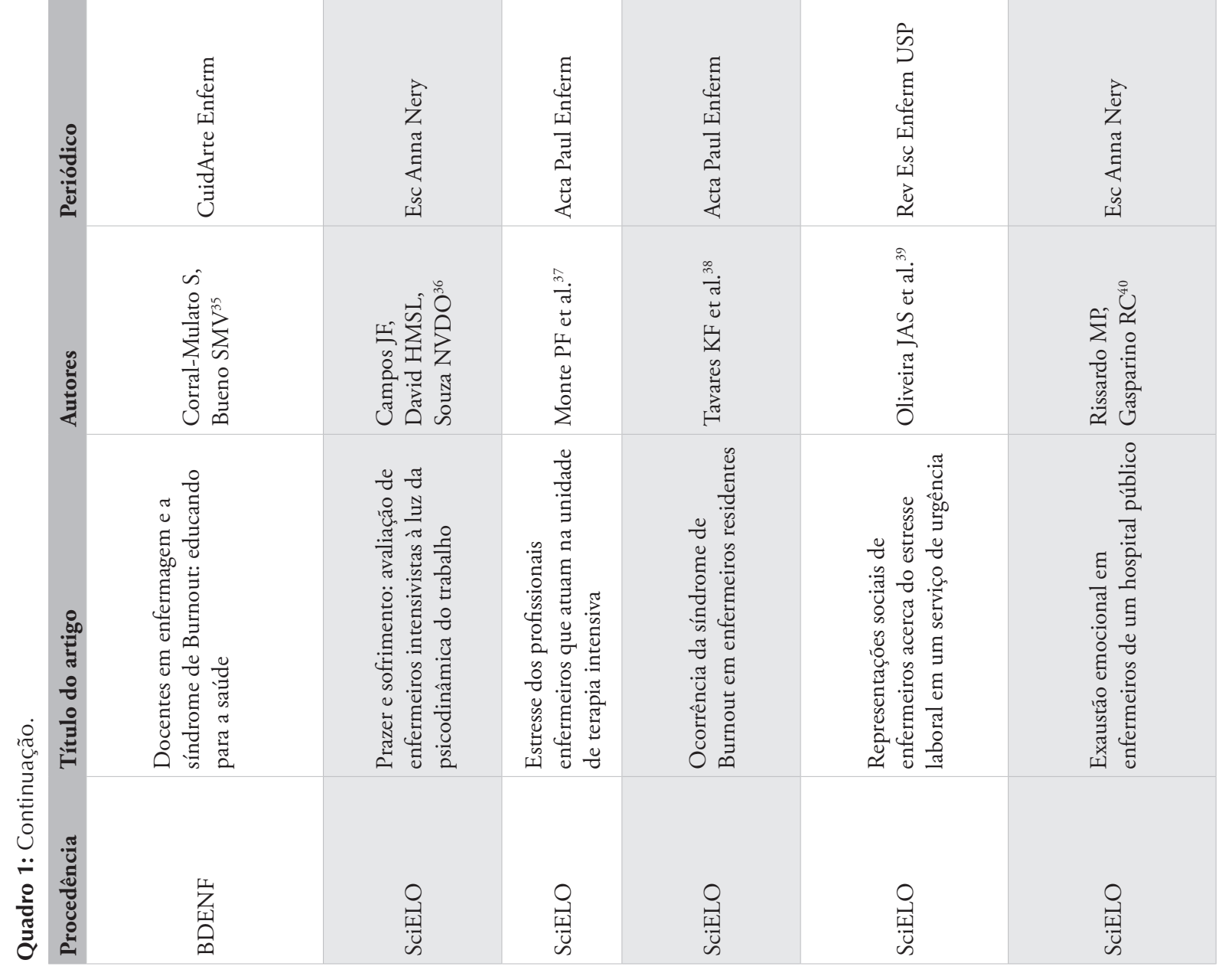




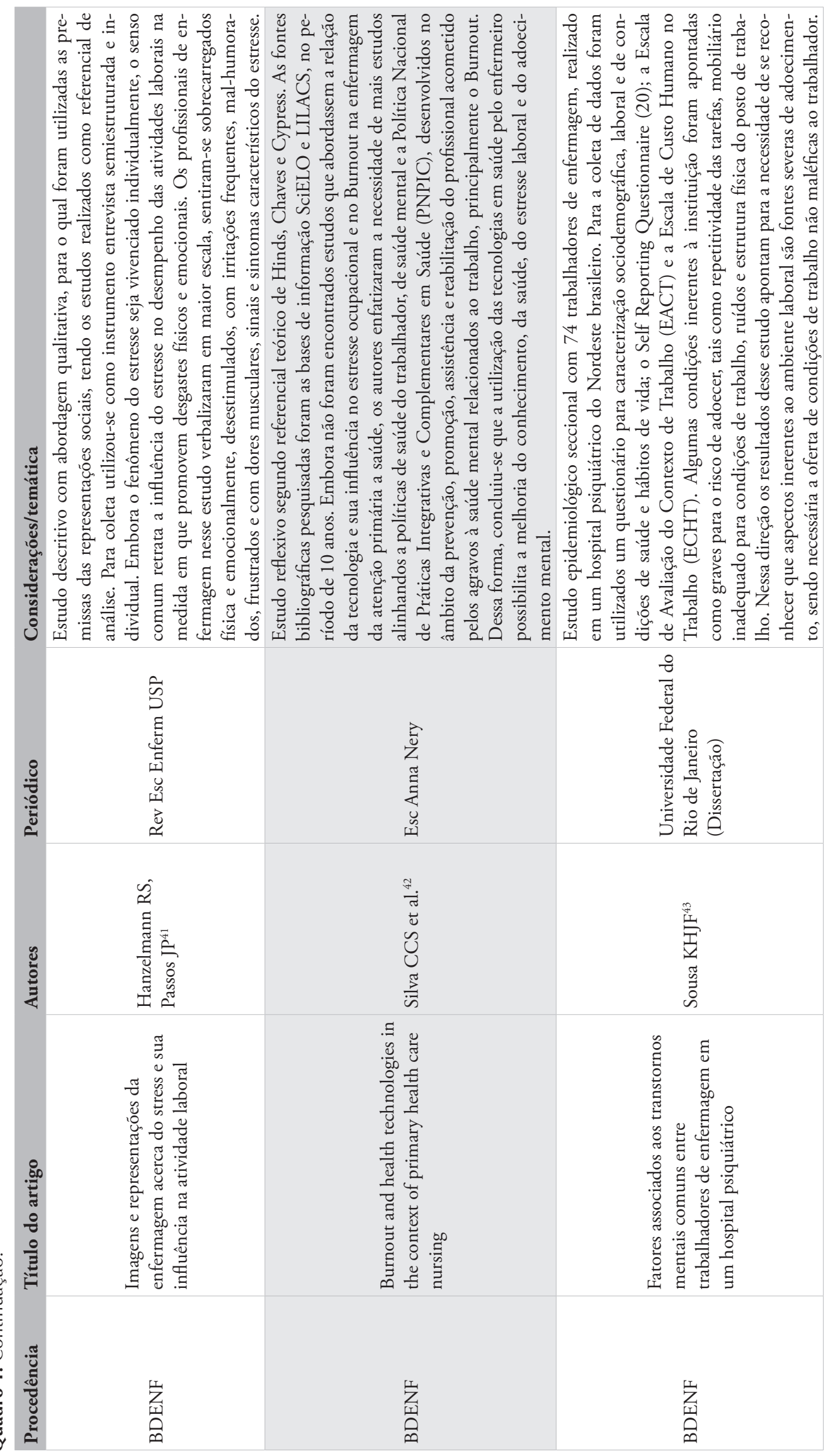


Assim, embora não tenha sido realizada qualquer estratégia para identificar o estresse ocupacional, vários profissionais enfermeiros e gestores de enfermagem reconhecem a importância de implementar o apoio psicológico para prevenção e tratamento do estresse relacionado à pressão no processo de trabalho ${ }^{25}$.

Estudos ressaltam sobre a importância de analisar a natureza psicossocial do trabalho, que passa a contribuir de maneira significativa para a melhoria da qualidade de vida laboral na enfermagem, assim como para fortalecer as açōes em segurança e saúde do trabalhador ${ }^{33,36}$.

Nota-se, entretanto, a escassez de pesquisas científicas que abordem e apoiem o tema específico quanto à identificação dos riscos e agravos e às possíveis soluçôes para a melhoria da qualidade do processo de trabalho da enfermagem ${ }^{28,35}$.

\section{Conclusões}

Os fatores de risco para adoecimento mental do enfermeiro e de sua equipe, de acordo com os estudos analisados e evidenciados nesta revisão, estão relacionados às condiçóes do trabalho e aos problemas de relacionamento interpessoal, destacando-se causas como dupla e longa jornada de trabalho, tensão entre setores de média e alta complexidade com pacientes vulneráveis e com risco eminente de morte, deficiência de recursos humanos e materiais, pressão da carga de serviço, burocratização, falta de autonomia, deslocamentos, rotinização, cobranças administrativas, humilhaçôes e ofensas, medo de demissão, entre outros, culminando em desgastes físicos, emocionais e mentais.

$O$ estresse frequente leva ao cansaço exaustivo, corroborando para a instalação da doença denominada Síndrome de Burnout, caracterizada pela exaustão emocional, despersonalização e baixo nível de realização profissional, que conforme a revisão apresenta os seguintes motivos determinantes de ocorrência: indivíduos jovens, do gênero feminino, solteiros, sem filhos, recém-formados e inseridos em setores de alta complexidade, embora não sejam excludentes os demais fatores e setores de trabalho.

Os fatores de risco explicitados no estudo trazem inúmeras implicaçôes no ambiente laboral à medida que situaçóes de estresse se tornam frequentes, provocando na equipe de enfermagem as manifestaçóes da SB, constatada na maioria dos estudos revisados, resultando na queda da qualidade da assistência, redução da produtividade, falta de interesse, insatisfação profissional, assim como no aumento de déficits psicossociais.

As estratégias de intervenção propostas na revisão para amenizar os riscos de estresse no ambiente de trabalho sugerem a diminuição da carga emocional pautando-se na ampliaçáo de recursos humanos e materiais suficientes para a demanda, valorização do trabalhador com jornada e remuneração justas e dignas, adoção de pausas esporádicas, introdução de tecnologias para maior aproveitamento e desempenho de tarefas, implementaçáo de atividades de educação permanente, grupos de reflexão, ginástica laboral e a necessidade de estudos alinhados com as políticas de saúde do trabalhador no âmbito da prevenção, promoção, assistência e reabilitação do profissional acometido pelos agravos à saúde mental relacionado à função.

Salienta-se que o estudo é de extrema relevância tanto para os profissionais em questâo, quanto para a sociedade no âmbito da saúde pública, pois é necessário melhorar as condições de serviço, a exposição aos riscos nas rotinas laborais, a fim de manter a qualidade de vida, a qualidade do trabalho, a qualidade da assistência de enfermagem e diminuir os índices de auxílio-doença por afastamentos, o absenteísmo e presenteísmo, bem como aposentadorias precoces que podem significativamente comprometer as condiçóes sociais e econômicas dos trabalhadores.

Assim, importante se faz a realização de pesquisas científicas sobre essa temática a fim de contribuir para a melhoria da qualidade de vida ocupacional e para o fortalecimento das açóes de segurança e saúde do trabalhador de enfermagem.

\section{Agradecimentos}

Agradecemos a Deus pela vida.

Aos nossos pais pela sólida formação e incentivo.

À professora doutora Silvana Tognini pela disposição e orientação na construção do estudo e aos demais docentes pelas contribuiçóes.

\section{Referências}

1. Cavalheiro G, Tolfo SR. Trabalho e depressão: um estudo com profissionais afastados do ambiente laboral. Psico-USF. 2011;16(2):241-9.

2. Pereira L. O trabalho em causa na epidemia depressiva. Tempo Social, Revista de Sociologia da USP. 2011; 23(1), 67-95.

3. Semen S, Garcez EMS. O adoecimento psíquico em profissionais da enfermagem. Rev. Saúde Pública. 2012;5(2):46-71.

4. Ministério da Previdência Social. Anuário estatístico da previdência social: 2010. Brasília, DF: Ministério da Previdência Social; 2011 [citado em 2017 maio 23]. Disponível em: https://goo.gl/Vz87M6 
5. Coren RS. Pesquisa aponta causas dos transtornos mentais provocados pelo ambiente de trabalho. Coren Rio Grande do Sul, 2013 [citado em 2017 maio 25]. Disponível em: https://goo.gl/p1YF2x

6. Rocha SV, Almeida MMG, Araujo TM, Virtuoso Junior JS. Prevalência de transtornos mentais comuns entre residentes de áreas urbanas de Feira de Santana, Bahia. Rev Bras Epidemiol. 2010;13(4):630-40.

7. Brasil. Anuário estatístico de acidentes do trabalho. Brasília, DF: Ministério da Previdência Social; 2014.

8. Caetano VC, Cruz DT, Leite ICG. Perfil dos pacientes e características do tratamento fisioterapêutico aplicado aos trabalhadores com LER/DORT em Juiz de Fora, MG. Fisioter Mov. 2010;23(3):451-60.

9. Lino MM, Nora PT, Furtado M. Enfermagem do trabalho à luz da visão interdisciplinar. Saúde Transform Soc. 2012;3(1):85-91.

10. Vasconcellos LCF, Gaze R. A integralidade e doenças dos trabalhadores: O método de Bernadino Ramazzini. In. Oficina de artigos da pós-graduação em Saúde Pública; 2009; Rio de Janeiro. [citado em 23 maio 2017]. Disponível em: <http:// www.segurancaetrabalho.com.br/download/ integral-fadel.pdf>.

11. Sprada E. Toxicologia. Curitiba: Instituto Federal do Paraná; 2013.

12. Vasconcellos LCF, Gaze R. Saúde, trabalho e ambiente na perspectiva da integralidade: o método de Bernardino Ramazzini. Revista da Faculdade de Serviços Social da UERJ. 2013;11(32):65-88.

13. Chibinski M. Como surgiu o conceito de segurança do trabalho: introdução à segurança do trabalho. Curitiba: Instituto Federal Paraná; 2011 [citado em 2018 maio 28]. Disponível em: https://goo.gl/MDu5yM

14. Andar Z. Trezentos anos depois: questáo atual. Jornal da Anamt; 2014 [citado em 2017 maio 25]. Disponível em: <https://goo.gl/6TGGuQ

15. Versa GLGS, Murassaki ACY, Inoue KC, Melo WA, Faller JW, Matsuda LM. Estresse ocupacional: avaliação de enfermeiros intensivistas que atuam no período noturno. Rev Gaúcha Enferm. 2012;33(2):78-85.

16. Trindade LL, Lautert L. Síndrome de burnout entre os trabalhadores da estratégia de saúde da família. Rev Esc Enferm USP. 2010;44(2):274-9.

17. Peres RS, Pereira MS, Xavier FTAX, Oliveira FM. Compartilhar para conviver: relato de uma intervenção baseada em grupos de encontro para abordagem de estressores ocupacionais. Rev. SPAGESP. 2011;12(1):14-21.

18. Linch CGF, Guido LA. Estresse de enfermeiros em unidade de hemodinâmica no Rio Grande do Sul, Brasil. Rev Gaúcha Enferm. 2011;32(1):63-71.

19. Alves ACGC. Estresse e o trabalho do enfermeiro: uma revisão bibliográfica [monografia]. Recife: Fundação Oswaldo Cruz; 2011.
20. Díaz-Rodriguez L, Arroyo-Morales M, CantareroVillanueva I, Fernandez-Lao C, Polley M, Fernández-delas-Peñas C. Uma sessão de Reiki em enfermeiras diagnosticadas com síndrome de Burnout tem efeitos benéficos sobre a concentração de IgA salivar e a pressão arterial. Rev Latino-Am Enfermagem. 2011;19(5):1132-8.

21. Araujo IMS. Médica do trabalho diz que estatísticas previdenciárias mostram crescimento de doenças mentais. Tribunal Regional do Trabalho da 16a Região Maranhão; 2016 [citado em 2017 maio 25]. Disponível em: https://goo.gl/DDYokq

22. Lorenz VR, Benatti MCC, Sabino MO. Burnout e estresse em enfermeiros de um hospital universitário de alta complexidade. Rev Latino-Am Enfermagem. 2010; 18(6):8 telas.

23. Ratochinski CMW, Powlowytsch PWM, Grzelczak MT, Souza WC, Mascarenhas LPG. O estresse em profissionais de enfermagem: uma revisão sistemática. R Bras Ci Saúde. 2016;20(4):341-6.

24. Silva FH. Estresse no trabalho de enfermeiros que atuam em hospitais privados segundo o modelo demanda-controle [dissertaçáo]. Rio de Janeiro: Universidade do Estado do Rio de Janeiro; 2015.

25. Mesquita KL, Gomes GPLA, Silva MJBF, Santos LF. A visão do enfermeiro/gestor sobre a necessidade de implementar apoio psicológico aos profissionais do serviço de atendimento móvel de urgência. R Enferm Cent O Min. 2014;4(1):1019-28.

26. Oliveira EB, Costa SLT, Guimarães NSL. O trabalho do acadêmico de enfermagem no hospital geral: riscos psicossociais. Rev Enferm UERJ. 2012;20(3):317-22.

27. França FM, Ferrari R. Síndrome de Burnout e os aspectos sócio-demográficos em profissionais de enfermagem. Acta Paul Enferm. 2012;25(5):743-8.

28. Traesel ES, Merlo ARC. Trabalho imaterial no contexto da enfermagem hospitalar: vivências coletivas dos trabalhadores na perspectiva da psicodinâmica do trabalho. Rev Bras Saúde Ocup. 2011;36(123):40-55.

29. Ferreira REDS. A organização do trabalho na Unidade de Doenças Infectocontagiosas e a ocorrência de Burnout nos trabalhadores de enfermagem [dissertação]. Rio de Janeiro: Universidade do Estado do Rio de Janeiro; 2011.

30. Ezaias GM, Gouvea PB, Haddad MCL, Vannuchi MTO, Sardinha DSS. Síndrome de Burnout em trabalhadores de saúde em um hospital de média complexidade. Rev Enferm UERJ. 2010;18(4):524-9.

31. Menzani G, Bianchi ERF. Stress dos enfermeiros de pronto socorro dos hospitais brasileiros. Rev Eletr Enf. 2009 [citado em 2018 maio 28];11(2):327-33. Disponível em: https://goo.gl/bZtPEM

32. Dalmolin GL, Lunardi VL, Lunardi Filho WD. O sofrimento moral dos profissionais de enfermagem no exercício da profissão. Rev Enferm UERJ. 2009;17(1):35-40.

33. Valença CN, Azevedo LMN, Oliveira AG, Medeiros SSA, Malveira FAS, Germano RM. A produção científica sobre a 
saúde do trabalhador de enfermagem. R Pesq Cuid Fundam. 2013;5(5):52-60.

34. Neves MJAO, Branquinho NCSS, Paranagua TTB, Barbosa MA, Siqueira KM. Influência do trabalho noturno na qualidade de vida do enfermeiro. Rev Enferm UERJ. 2010;18(1):42-7.

35. Coral-Mulato S, Bueno SMV. Docentes em enfermagem e a síndrome de Burnout: educando para a saúde. CuidArte Enferm. 2009;3(2):99-104.

36. Campos JF, David HMSL, Souza NVDO. Prazer e sofrimento: avaliação de enfermeiros intensivistas à luz da psicodinâmica do trabalho. Esc Anna Nery. 2014;18(1):90-95.

37. Monte PF, Lima FE, Neves FM, Studart RM, Dantas RT. Estresse dos profissionais enfermeiros que atuam na unidade de terapia intensiva. Acta Paul Enferm. 2013;26(5):421-7.

38. Tavares KF, Souza NV, Silva LD, Kestenberg CC. Ocorrência da síndrome de Burnout em enfermeiros residentes. Acta Paul Enferm. 2014;27(3):260-5.
39. Oliveira JAS, Alchieri JC, Pessoa Junior JM, Miranda FAN, Almeida MG. Representaçóes sociais de enfermeiros acerca do estresse laboral em um serviço de urgência. Rev Esc Enferm USP. 2013;47(4):984-9.

40. Rissardo MP, Gasparino RC. Exaustão emocional em enfermeiros de um hospital público. Esc Anna Nery. 2013;17(1):128-32.

41. Hanzelmann RS, Passos JP. Imagens e representações da enfermagem acerca do stress e sua influência na atividade laboral. Rev Esc Enferm USP. 2010;44(3):694-701.

42. Silva CCS, Lira ALBC, Feijao AR, Costa IKF, Medeiros SM. Burnout and health technologies in the context of primary health care nursing. Esc Anna Nery. 2017; 21(2):e20170031.

43. Sousa KHJF. Fatores associados aos transtornos mentais comuns entre trabalhadores de enfermagem em um hospital psiquiátrico [dissertação]. Rio de Janeiro: Universidade Federal do Rio de Janeiro; 2017.

\section{Como citar este artigo:}

Munhoz CS, Dantas TGM, Ríncon LAA, Tognini S. Fatores de risco para o transtorno mental relacionado ao trabalho em profissionais de enfermagem. Rev. Aten. Saúde. 2018;16(56):83-93. 